\title{
Review Article \\ Ovarian Epithelial-Stromal Interactions: Role of Interleukins 1 and 6
}

\author{
Kamisha T. Woolery ${ }^{1}$ and Patricia A. Kruk ${ }^{1,2}$ \\ ${ }^{1}$ Department of Pathology \& Cell Biology, MDC 11, University of South Florida, 12901 Bruce B. Downs Blvd., Tampa, \\ FL 33612, USA \\ ${ }^{2}$ H. Lee Moffitt Cancer Center, Tampa, FL 33612, USA
}

Correspondence should be addressed to Patricia A. Kruk, pkruk@health.usf.edu

Received 1 February 2011; Revised 12 April 2011; Accepted 27 April 2011

Academic Editor: Eddie Murta

Copyright $\odot 2011$ K. T. Woolery and P. A. Kruk. This is an open access article distributed under the Creative Commons Attribution License, which permits unrestricted use, distribution, and reproduction in any medium, provided the original work is properly cited.

\begin{abstract}
Ovarian epithelial cancer is the most lethal gynecologic malignancy. The high mortality is attributed to the fact that most cases typically present in late stage when ovarian cancer (OC) has already spread beyond the ovary. Ovarian epithelial cancer cells are shed into intraperitoneal ascites and easily disseminate throughout the peritoneal cavity with preferential metastasis to the omentum, peritoneum, and local organs. Understanding how ovarian epithelial cells interact with and modulate their microenvironment can provide insight into the molecular mechanism(s) involved with malignant transformation and progression which may eventually identify novel diagnostic, prognostic, and therapeutic targets. The objective of this paper is to provide a brief consideration of ovarian surface epithelial-stromal interactions in regard to normal physiological function and tumor progression as influenced by two potentially key interleukins, interleukins-1 (IL-1) and -6 (IL-6), present in the microenvironment. Lastly, we will consider the clinical implications of IL-1 and IL-6 for OC patients.
\end{abstract}

\section{Introduction}

Ovarian cancer (OC) is the leading cause of gynecologic cancer death in women in the US. It is the fourth leading cause of cancer death among women after lung, breast, and colorectal cancer and is associated with a $1.7 \%$ lifetime risk [1-4]. It is estimated that 23,100 new cases are diagnosed in the US annually [4] and that 14,000 women die annually from this disease. The one-year survival rate for OC can be as high as $79 \%$ and when diagnosed in an early stage the 5-year survival rate is almost 95\% [4]. However, when diagnosed at a later stage, the 5-year survival is generally no better than 35\% [4]. Optimal cytoreduction followed by platinumbased chemotherapy remains the mainstay of therapy in the management of advanced epithelial ovarian cancers [2]. However, while the response rate to primary chemotherapy can be as high as $76 \%$, response rate is dramatically reduced after relapse of disease [5]. Platinum resistance, defined as disease recurrence less than six months from completion of therapy, is an important prognostic predictor. Patients with platinum-resistant tumors have a response rate of less than $10 \%$ when retreated with platinum compounds $[6,7]$ and alternative options also have poor response rates of $18-30 \%$ [8-15].

Ovarian surface epithelium-(OSE-) derived tumors account for $90 \%$ of malignant ovarian tumors with serous tumors accounting for over 30\% of all OSE-derived cancers [16]. The majority of ovarian cancers are sporadic in origin, but about $10 \%$ of all epithelial ovarian carcinomas are associated with a hereditary predisposition and are characterized by an increased incidence and earlier onset of disease [17]. Epidemiological studies suggest that besides race [18] and familial history of breast or ovarian cancer [19-21], events associated with OSE traumatization may result in aberrant OSE growth leading to ovarian epithelial carcinogenesis [22]. Thus, increased age, reproductive history (nulliparity), early menarche, late menopause, and fertility drug use increase the risk for OC. In contrast, suppression of ovulation by pregnancy, lactation, or oral contraceptive use decrease the risk for OC. Lifestyle factors including dietary fat intake and 
smoking may also increase the risk for OC while dietary intake of vitamins $\mathrm{A}, \mathrm{C}, \mathrm{D}$, and $\mathrm{E}$ may protect against OC [23-25].

The high mortality associated with this disease is generally attributed to the fact that most cases typically present in late stage when OC has already spread beyond the ovary, that the disease is generally asymptomatic in early stages, and that an effective screening test is lacking $[25,26]$. In addition to involving the ovary, ovarian epithelial cancer cells are shed into intraperitoneal ascites fluid and easily disseminate throughout the peritoneal cavity with preferential mestastasis to the omentum and peritoneum as well as other local organs.

The etiology of OC is not completely known and can be attributed to genetic instability associated with repeated repair of ovulatory defects, elevated gonadotropin levels with inclusion cysts, or explantation of Fallopian tube material. Understanding how ovarian epithelial cells interact with and modulate their microenvironment contributing to cancer initiation and progression can provide insight into molecular mechanism(s) involved with malignant transformation which may eventually identify novel diagnostic, prognostic, and therapeutic targets. Interleukin-1 (IL-1) and interleukin-6 (IL-6) may prove to be such targets. Both cytokines contribute to the progression of $\mathrm{OC}$ by promoting angiogenesis, metastasis, and chemoresistance. The main focus of this paper, then, will be to briefly describe the role of IL-6 in OC progression and to more thoroughly examine the role of the lesser understood IL-1 in relation to OC progression and its capacity as a possible therapeutic target. This paper was conducted using a broad literature survey encompassing the past 25 years of basic and clinical research publications exploring IL-1 and IL-6 as each pertains to ovarian cancer prognosis, progression, and treatment.

\section{Ovarian Surface Epithelium: Extracellular Matrix Interactions}

Despite the fact that over $85 \%$ of ovarian cancers arise from and/or involve the OSE $[2,50]$, the reasons for the propensity of OC development are still poorly understood. However, due to the common embryonic origin of OSE with the epithelia lining Fallopian tube, endometrium, and cervix, histologic subtypes of OSE-derived tumors include serous, endometrioid, and mucinous tumors, respectively. Likewise, the expression of stromal characteristics by OSE cells may be related to their shared mesodermal origin from the coelomic epithelium and to their close developmental relationship to ovarian stromal fibroblasts. For example, OSE express both vimentin and keratin intermediate filaments characteristic of connective tissue and epithelium, respectively [51]. Further, when maintained on collagen type I gel, OSE cells undergo a modulation into a spindle-like morphology which accompanies collagen gel contraction [52]. In contrast, OSE cells invade Matrigel and can remodel extracellular matrix (ECM) by secretion of collagenase, gelatinase and stromelysin as well as produce laminin and collagens I, III and IV $[53,54]$. Consequently, the interaction with stroma and the ability of OSE to produce, lyse, and reconstruct ECM indicates that OSE has the capacity to undergo epithelialmesenchymal conversions which may not only be necessary for restoring the integrity of the OSE following ovulatory damage, but may also contribute to invasion and metastasis with malignant transformation of the OSE.

\section{Ovarian Cancer and Epithelial-Mesenchymal Transition}

Epithelial-mesenchymal transition (EMT) is characterized by the disruption of cellular junctions and loss of cellular polarity resulting in morphologic modulation into a fibroblastic phenotype accompanied by increased cell motility and invasion [55]. Embryonically, EMT contributes to gastrulation, and in the ovary to gonadal development [56]. During tissue repair following ovulation, OSE undergoes EMT in response to its local microenvironment into a fibroblast-like phenotype which promotes OSE migration, proliferation, and matrix remodeling to repair the ovulatory defect. "Incessant ovulation" proposes that repeated injury to the OSE with subsequent rounds of cellular proliferation cannot only lead to the acquisition of replicative DNA errors contributing to genetic instability and ensuing malignant transformation [57], but also to chronic inflammation [58]. Such inflammation is associated with oxidative stress and recruitment of activated immune cells, including macrophages, T cells, B cells, natural killer cells, neutrophils, and granulocytes [59] resulting in a locally marked increase in cytokines/chemokines (interleukins and tumor necrosis factors) and matrix-remodeling enzymes (plasminogen activators and collagenases) that can also promote tumor formation [57].

EMT and subsequent mesenchymal-epithelial (MET) transitions associated with alterations of E-cadherin expression [60] are among the most dramatic examples of OSE plasticity in response to its microenvironment and represent critical steps in ovarian tumor progression. Owing to the mesodermal origin of OSE, normal OSE express $\mathrm{N}$-cadherin, but not E-cadherin. However, in contrast to loss of E-cadherin expression with tumor progression in most epithelial cancers, E-cadherin is often reexpressed in OSE lining crypts and inclusion cysts as well as in benign, borderline, and primary ovarian cancers [60]. Importantly, given that OC metastasizes by shedding into the peritoneal cavity as single cells or cell clusters, transient E-cadherin reexpression maintains OC aggregate formation and survival in the peritoneal cavity [61]. OC aggregates, mesothelial cells, and surrounding blood cells all secrete cytokines that support OC survival in ascites so that both autocrine and paracrine mechanisms sustain OC EMT in ascites fluid and promote establishment of metastatic disease. The reverse process of MET results from loss of transient E-cadherin expression so that established metastasticovarian cancers are frequently devoid of E-cadherin [62]. Pathways promoting EMT in OSE rely on complex interactions between OSE and its extracellular components and consist of autocrine and 
paracrine interactions with hormones and cytokines including transforming growth factor- $\beta$ [63], epidermal growth factor [64], hepatocyte growth factor [65], endothelin-1 [66], and bone morphogenic protein 4 (BMP4) [67]. Interestingly, epidermal growth factor/epidermal growth factor receptor signaling induces EMT in cultures of OC cell lines and is also associated with enhanced expression and secretion of IL-6, resulting in increased cellular motility [68].

In addition to promoting a migratory and invasive phenotype, EMT may contribute to patient mortality by conferring paclitaxel resistance in epithelial ovarian cancer cells [69], inducing myocyte differentiation into CD14+/KDR+ proangiogenic cells thereby promoting tumor angiogenesis and vascularization [70], and inducing the differentiation of stromal mesenchymal stem cells into tumor associated fibroblasts that support disease progression through matrix remodeling [41]. In this last context, it is interesting that both in vivo and in vitro studies indicate that IL-6 produced by stromal tumor associated fibroblasts also enhances OC cell proliferation through activated signal transducer and activator of transcription 3 (STAT3) signaling [41].

While nonsteroidal anti-inflammatory drugs (NSAIDS) have failed to protect against development of OC [71, 72], inflammation may still contribute to the clinical development of OC. In addition to presenting as an inflammatory disease, inflammation of the ovarian epithelium has been associated with increased risk for OC $[58,73-75]$ and endometriosis is associated risk for clear cell carcinoma of the ovary [71, 76-79]. Consequently, the potential clinical contribution of inflammatory mediators, IL-6 and IL-1, for ovarian tumor initiation and progression should not be overlooked.

\section{Interleukin-6}

IL-6 is a pleiotropic cytokine that plays a major role in the immune system in response to injury and infection, as well as, inflammation [45]. IL-6 is produced by T cells, monocytes, fibroblasts, endothelial cells, and keratinocytes [80]. Depending on the experimental system, IL-6 has been suggested to have both proinflammatory and antiinflammatory properties in vitro and in vivo [81]. However, it appears that IL-6 acts predominately as an antiinflammatory and immunosuppressive cytokine by directly suppressing IL-1 and tumor necrosis factor- $\alpha$ (TNF- $\alpha$ ), inducing release of glucocorticoids, and inducing natural antagonists to IL- 1 and TNF- $\alpha$ [81]. In an in vitro prostate cancer model, cancer-associated fibroblasts secreted higher amounts of IL-6 than normal fibroblasts which resulted in an increased proliferation of normal epithelial cells and increased endothelial cell migration towards the cancerassociated fibroblasts and/or their conditioned media [82]. It is not surprising then that Spaeth et al. [41] found that tumor-associated fibroblasts derived and differentiated from mesenchymal stromal stem cells produced and secreted IL-6 that similarly promoted OC cell proliferation [41].

In the normal ovary, aside from production by activated stromal immune cells, IL-6 is produced by granulosa cells
[83] and OSE cells $[84,85]$. However, neoplastic ovarian cells also routinely overexpress IL-6 in vitro [84-86] and greater amounts of IL-6 are present in the cystic fluid of malignant tumors when compared to cystic fluid of benign tumors [80]. Likewise, OC ascites are rich in IL-6 [46, 87-89]. Consequently, elevated levels of IL-6 in the blood and ascites are associated with poor prognosis in OC [90]. Interestingly, elevated serum IL-6 levels are uniquely associated with OC compared to other gynecological malignancies and although this is a much less sensitive biomarker for OC than CA125 [46], it may still serve as a useful prognostic indicator of disease.

While the role of IL-6 in the etiology of OC is not fully understood, we might predict that IL- 6 contributes to OC by promoting angiogenesis, tumor invasion, and chemoresistance. Specifically, in vivo treatment with IL-6-induced angiogenesis and enhanced endothelial cell-mediated migration of human ovarian carcinoma cells [42]. IL-6 may also be involved in the tumorigenic processes of $\mathrm{OC}$ cell lines by increasing their capacity to secrete matrix metalloproteinase9 (MMP-9) [43]. Further, OC cell lines cultured with IL6 demonstrate increased chemotactic and/or chemokinetic activity and increased overall invasiveness [44]. Overexpression of IL-6 is also associated with chemoresistance in OC cells $[46,47]$. In vitro studies of OC cell lines further show that autocrine production of IL- 6 decreased their responsiveness to cisplatin and paclitaxel [45].

Interestingly both IL-6 and IL-1 levels are elevated in ascites. In vitro studies show that treatment of granulosa cells with IL-1 increases IL-6 production in a dose-dependent manner [83] and, likewise, treatment of OC cell lines with IL$1 \beta$, lead to increased secretion of IL-6 [91]. Consequently, the contribution of IL- 1 to initiate and promote OC progression by regulating IL-6 expression deserves consideration.

\section{Interleukin-1}

There are 11 members of the IL-1 cytokine family that have proinflammatory or anti-inflammatory activity. The most thoroughly studied cytokines from this family are two agonist cytokines: IL- $1 \alpha$ and IL- $1 \beta$ and one antagonist cytokine: interleukin-1 receptor antagonist (IL-1Ra). Though all of these cytokines are associated with chronic inflammatory diseases (CIDs), IL- $1 \beta$ appears to be the primary mediator of inflammation in CIDs [39].

IL- $1 \beta$ is synthesized in a precursor form as a $31 \mathrm{kD}$ protein that is cleaved by caspase- 1 into its active $17 \mathrm{kD}$ mature secreted form [92]. IL- $1 \beta$ is mainly produced by monocytes and macrophages, but can also be produced by endothelial cells, fibroblasts, and epidermal cells in response to bacterial or innate immunity stimulation [93]. Both normal and malignant epithelial ovarian cells also produce IL-1 [90], although activated immune cells in the stroma remain the major source of IL-1 [94]. Constitutive production of IL$1 \beta$ by ovarian carcinoma cells [95] enhances their invasion capacities by increasing expression of MMP-1 [36] and stimulating production of proangiogenic factors such as vascular endothelial growth factor (VEGF) [37]. Additionally, 
fibroblasts cultured with conditioned media from a highly metastatic OC cell line or with IL- $1 \beta$ induced transformation of the fibroblasts to myofibroblasts expressing $\alpha$-smooth muscle actin ( $\alpha$-SMA) [38]. This coincided with induction of myofibroblast expression of fibroblast activation protein (FAP), a cell-surface serine protease with capacity to remodel ECM by cleaving collagen type 1 [38], thereby promoting OC cell migration and invasion.

IL- $1 \alpha$ is likewise synthesized in a precursor form as a $31 \mathrm{kD}$ protein that is cleaved by $\mathrm{Ca}^{2+}$-dependent protease calpain into an active $17 \mathrm{kD}$ mature cell-associated form $[28,92]$. IL- $1 \alpha$ is produced by monocytes, macrophages, epithelial cells, keratinocytes, and fibroblasts [96]. However, because it remains mainly cell-associated, IL- $1 \alpha$ induces less inflammation and angiogenesis than IL-1 $\beta$ [27]. Further, since IL- $1 \alpha$ is generally secreted to a lesser extent than IL$1 \beta$, it is not commonly detected in bodily fluids except when released from necrotizing cells in cases of severe inflammation [28]. In its cell-associated form, IL- $1 \alpha$ mainly acts as a tumor suppressor in malignant cells by recruiting immunocompetent cells to the tumor microenvironment and assisting in an immunologic response to combat tumor growth [28-31]. IL- $1 \alpha$ tumor suppressor characteristics have been further confirmed in vivo where IL- $1 \alpha$ produced by tumorigenic fibroblasts decreased the number of tumor growths, as well as increased tumor rejection by facilitating activation and expansion of helper $\mathrm{T}$ cells $[32,33]$. Consequently, in OC, IL- $1 \beta$ generally promotes invasiveness, tumor angiogenesis and induces immune suppression while IL- $1 \alpha$ reduces tumorigenicity by inducing antitumor immunity [97].

Lastly, IL-1Ra is an antagonist that inhibits IL- $1 \alpha$ and IL$1 \beta$ from binding to both IL- 1 receptors, but does not activate IL-1 receptor cell signaling cascades. IL-1Ra is secreted by the same cell types as IL- $1 \alpha$ and IL- $1 \beta$ including monocytes, macrophages, and OSE [98]. Further, high levels of IL-1Ra in cultured tumor-derived macrophages compared to cultured tumor-derived ovarian epithelial cells [99] suggest that the major contributors of IL-1Ra are activated macrophages. IL-1Ra is excessively abundant in the ascites of late-stage OC patients compared to IL-1Ra levels in ascites and/or serum levels from early-stage OC and benign ovarian tumors [40]. Higher levels of IL-1Ra in ascites and/or serum appear associated with poor prognosis and reduced overall survival [40]. Since IL-1Ra does not activate IL-1 receptor cell signaling cascades and IL-1Ra production can be induced by IL- $1 \beta$ and/or IL- $1 \alpha$, it is plausible that the increased IL-1Ra in the ascites and the associated poor prognosis is due to secreted IL- $1 \beta$ signaling [31]. In agreement, Mustea et al. found that increased levels of IL- $1 \beta$ in the serum and/or ascites were associated with decreased survival [40]. Therefore, it is imperative to further understand the clinical significance of the IL-1 family in the progression of OC as well as potential treatment targets.

\section{Clinical Relevance}

Phase I and II clinical trials utilizing recombinant human IL6 in conjunction with chemotherapy increased OC patient platelet count alleviating thrombocytopenia $[48,49]$, thereby comprising adjuvant therapeutic benefits of IL-6. As stated earlier, IL-1 increases production of IL-6 [83, 91]; therefore, due to this interrelationship, studies investigating the effect of IL-1 on the development of OC are clinically important. A better understanding of the IL-1 cytokines' functions in relationship to OC may help to identify novel prophylactic drug treatments and/or treatments after disease occurrence.

As described earlier, IL- $1 \alpha$ has tumor suppressor functions that should be further investigated in OC; however, the effectiveness of IL- $1 \alpha$ as a treatment option is likely limited to early onset of disease. When released in its precursor form, such as from necrotic tumor cells under hypoxic conditions commonly seen in OC [96], IL- $1 \alpha$ can promote an inflammatory response perpetuating the chronic inflammation associated with the onset of disease [96]. Yet, when released in its cleaved form, IL- $1 \alpha$ lacks the ability to interact with its receptor [96] so that treatment with the precursor form would be expected to elicit a proinflammatory response and treatment with the cleaved form would elicit no response.

On the other hand, in vitro studies have shown that IL- $1 \alpha$ increases $11 \beta$-hydroxysteroid dehydrogenase type 1 (11 $\beta$ HSD1) mRNA expression in human primary OSE [100] leading to increased rates of cortisone to cortisol conversion by OSE [101] promoting cortisol's anti-inflammatory potential [102]. However, since $11 \beta$-hydroxysteroid dehydrogenase type 2 (11ßHSD2) activity is greater in OC tissue compared to normal ovarian tissue [103], it is not surprising that OC cell lines treated with IL- $1 \alpha$ in vitro induced $11 \beta \mathrm{HSD} 2$ gene expression leading to the reverse conversion of cortisol to cortisone inactivating the antiinflammatory actions of $11 \beta \mathrm{HSD} 1$ and, thereby, supporting tumor cell proliferation [104]. Consequently, the IL- $1 \alpha$ induced switch from $11 \beta \mathrm{HSD} 1$ to $11 \beta \mathrm{HSD} 2$ associated with malignant transformation confers a growth advantage to $\mathrm{OC}$ cells [105] and limits the therapeutic potential of IL- $1 \alpha$.

A phase I clinical trial showed recombinant human IL$1 \alpha$ treatment having minor antitumor effect in advanced recurrent ovarian cancer [106]. Nonetheless, clinical trials showed that recombinant human IL- $1 \alpha$ treatment accelerated platelet recovery during chemotherapy and reduced carboplatin-induced thrombocytopenia in patients with recurrent OC [34], as well as in patients with ovarian and other cancer types (gastrointestinal, breast, melanoma, lung, head and neck, sarcoma, and prostate) who did not receive concomitant chemotherapy [35]. However, IL-6 is an effective hematopoietic growth factor and plays a direct role in megakaryocyte differentiation into platelets [48]. Therefore, it can be hypothesized that the platelet increase seen in response to recombinant human IL- $1 \alpha$ treatment could also be due to IL-1-induced production of IL-6 [35]. Therefore, more clinical trials should be completed to test the efficiency of IL-1 and/or IL-6 to ameliorate thrombocytopenia.

In contrast, due to IL- $1 \beta$ 's cancer-promoting activities, inhibiting IL- $1 \beta$ function represents a promising new avenue for therapeutic intervention. Developing novel IL- $1 \beta$ antagonists that block IL- $1 \beta$ 's ability to bind to its receptor should suppress IL- $1 \beta$ 's VEGF-mediated angiogenesis, invasiveness, 
TABle 1: Proposed functions of IL-1 and IL-6 in OC.

\begin{tabular}{|c|c|c|c|c|}
\hline Cytokine & Inflammatory fnction & Proposed function in ovarian cancer & Model & Ref. \\
\hline \multirow{3}{*}{ IL- $1 \alpha$} & \multirow{3}{*}{ Proinflammatory } & (i) Stimulate angiogenesis & (i) In vitro/In vivo & {$[27]$} \\
\hline & & (ii) Recruit immunocompetent cells & (ii) In vitro/In vivo & [28-33] \\
\hline & & (iii) Increase platelet count & (iii) Phase I clinical trial & {$[34,35]$} \\
\hline \multirow{3}{*}{ IL- $1 \beta$} & \multirow{3}{*}{ Proinflammatory } & (i) Increase expression of MMP-1 & (i) In vitro & {$[36]$} \\
\hline & & $\begin{array}{l}\text { (ii) Stimulate production of } \\
\text { proangiogenic factors }\end{array}$ & (ii) In vitro & {$[37]$} \\
\hline & & $\begin{array}{l}\text { (iii) Promote OC cell migration and } \\
\text { invasion }\end{array}$ & (iii) In vitro & {$[38]$} \\
\hline \multirow{2}{*}{ IL-1Ra } & \multirow{2}{*}{ Anti-inflammatory } & (i) Antagonist to IL- $1 \alpha$ and IL- $1 \beta$ & & {$[39]$} \\
\hline & & (ii) Abundant in the OC ascites & In vivo & {$[31,40]$} \\
\hline \multirow{8}{*}{ IL-6 } & \multirow{8}{*}{ Anti-inflammatory } & (i) Promote OC cell proliferation & (i) In vitro & {$[41]$} \\
\hline & & (ii) Stimulate angiogenesis & (ii) In vitro/In vivo & {$[42]$} \\
\hline & & $\begin{array}{l}\text { (iii) Enhance endothelial cell } \\
\text { migration }\end{array}$ & (iii) In vitro/In vivo & {$[42]$} \\
\hline & & $\begin{array}{l}\text { (iv) Increase OC cell lines capacity to } \\
\text { secrete MMP-9 }\end{array}$ & (iv) In vitro & {$[43]$} \\
\hline & & $\begin{array}{l}\text { (v) Increase chemotactic and/or } \\
\text { chemokinetic activity }\end{array}$ & (v) In vitro & {$[44]$} \\
\hline & & (vi) Increase invasiveness & (vi) In vitro & {$[44]$} \\
\hline & & (vii) Induce chemoresistance & (vii) In vitro/In vivo & [45-47] \\
\hline & & (viii) Increase platelet count & (viii) Phase I and II clinical trial & {$[48,49]$} \\
\hline
\end{tabular}

and chemoresistance. While published clinical trials of IL$1 \beta$ as a therapeutic target in treatment of cancer is limited, a phase I trial showed treatment with recombinant human IL- $1 \beta$ elevated platelet levels in patients with gastrointestinal cancer [107]. However, as stated earlier, IL-1's ability to increase platelet levels may be partially due to inducing production of IL- 6 . However, due to the aggressiveness of OC and IL- $1 \beta$ 's promotion of cancer progression, it may prove more beneficial to evaluate IL- $1 \beta$ as a treatment target rather than as a therapeutic agent. Therefore, as a treatment target effective agents would likely mimic the action of IL-1 $\beta$ 's natural antagonist and/or neutralize IL- $1 \beta$. Currently, a recombinant IL-1Ra, Anakinra, which blocks IL$1 \beta$ and IL- $1 \alpha$ from binding to their receptors, is used for the treatment of rheumatoid arthritis [108]. Likewise, the fusion glycoprotein, Rilonacept, which works by binding to IL- $1 \alpha$ and IL- $1 \beta$ with high affinity to neutralize both molecules is yet another anti-inflammatory therapy currently in use [108]. Lastly, Canakinumab, a fully humanized monoclonal antibody highly specific for IL- $1 \beta$, is currently in clinical use to suppress inflammation [108]. Consequently, these approved or similarly targeted inflammatory medications may be valuable for their capability to reduce IL-1-induced disease processes that promote OC.

\section{Conclusion}

In conclusion, IL-1 and IL-6 significantly impact the ovarian cancer physiologic and structural microenvironment. Specifically, either cytokine can promote proliferative, migratory and invasive changes in ovarian cancer cells. Clinically recombinant IL-1 and IL-6 may alleviate chemotherapyinduced thrombocytopenia. Furthermore, IL- $1 \beta$ neutralizing treatments, such as those employed in autoinflammatory diseases, combined with chemotherapy may prove beneficial to reduce IL- $1 \beta$-mediated angiogenesis and metastasis.

This paper has explored the cancer-promoting aspects of IL-1 and IL-6 summarized in Table 1, as well as, their beneficial characteristics in alleviating a chemotherapy side effect. There is a delicate balance that must be achieved between using IL-1 and IL-6 for therapeutic purposes, while also abrogating the cancer-promoting characteristics of each cytokine. Consequently, further experimental and clinical studies of IL-1 and IL-6 are warranted and may provide a better understanding of interleukin-associated changes to the microenvironment associated with ovarian cancer progression leading to improved prognosis by novel treatment options.

\section{Abbreviations}

CIDs: $\quad$ Chronic inflammatory diseases

BMP4: $\quad$ Bone morphogenic protein 4

ECM: $\quad$ Extracellular matrix

11 $\beta$ HSD 1: $11 \beta$-hydroxysteroid dehydrogenase type 1

$11 \beta$ HSD2: $11 \beta$-hydroxysteroid dehydrogenase type 2

IL-1: $\quad$ Interleukin-1

IL-1Ra: Interleukin-1 receptor antagonist

IL-6: Interleukin-6

EMT: Epithelial-mesenchymal transition

FAP: $\quad$ Fibroblast activation protein

MET: Mesenchymal-epithelial transition 
MMP: Matrix Metalloproteinase

NSAIDS: Nonsteroidal anti-inflammatory drugs

OC: Ovarian cancer

OSE: Ovarian surface epithelium

$\alpha$-SMA: $\alpha$-smooth muscle actin

STAT3: Signal transducer and activator of transcription 3

TNF- $\alpha$ : Tumor necrosis factor- $\alpha$

VEGF: Vascular endothelial growth factor.

\section{Acknowledgments}

This work was supported, in part, by a grant from the Ovarian Cancer Research Fund GRT 10935 (PAK) and a National Sciences Foundation Florida-Georgia Louis Stokes for Alliance Minority Participation (FGLSAMP) Bridge to the Doctorate Award HRD no. 0929435 (KTW).

\section{References}

[1] W. J. Hoskins, "Prospective on ovarian cancer: why prevent?" Journal of Cellular Biochemistry, vol. 59, no. 23, supplement, pp. 189-199, 1995.

[2] R. F. Ozols, "Ovarian cancer, Part II: treatment," Current Problems in Cancer, vol. 16, no. 2, pp. 67-126, 1992.

[3] R. E. Scully, "Pathology of ovarian cancer precursors," Journal of Cellular Biochemistry, vol. 59, no. 23, pp. 208-218, 1995.

[4] R. T. Greenlee, T. Murray, S. Bolden, and P. A. Wingo, "Cancer statistics, 2000," Ca-A Cancer Journal for Clinicians, vol. 50, no. 1, pp. 7-33, 2000.

[5] E. C. Kohn, G. Sarosy, A. Bicher et al., "Dose-intense taxol: high response rate in patients with platinum-resistant recurrent ovarian cancer," Journal of the National Cancer Institute, vol. 86, no. 1, pp. 18-24, 1994.

[6] G. Blackledge, F. Lawton, C. Redman, and K. Kelly, "Response of patients in phase II studies of chemotherapy in ovarian cancer: implications for patient treatment and the design of phase II trials," British Journal of Cancer, vol. 59, no. 4, pp. 650-653, 1989.

[7] J. T. Thigpen, J. A. Blessing, H. Ball, S. J. Hummel, and R. J. Barrett, "Phase II trial of paclitaxel in patients with progressive ovarian carcinoma after platinum-based chemotherapy: a Gynecologic Oncology Group study," Journal of Clinical Oncology, vol. 12, no. 9, pp. 1748-1753, 1994.

[8] G. J. Creemers, G. Bolis, M. Gore et al., "Topotecan, an active drug in the second-line treatment of epithelial ovarian cancer: results of a large European phase II study," Journal of Clinical Oncology, vol. 14, no. 12, pp. 3056-3061, 1996.

[9] A. Gordon, J. Carmichael, and J. Malfetano, "Final analysis of a phase III randomized study of topotecan vs. paclitaxel in advanced epithelial ovarian cancer," International Topotecan Study Group, vol. 17, article 356a, 1997.

[10] M. Kaufmann and G. von Minckwitz, "Gemcitabine in ovarian cancer: an overview of safety and efficacy," European Journal of Cancer Part A, vol. 33, no. 1, supplement, pp. S31S33, 1997.

[11] F. M. Muggia, J. D. Hainsworth, S. Jeffers et al., "Phase II study of liposomal doxorubicin in refractory ovarian cancer: antitumor activity and toxicity modification by liposomal encapsulation," Journal of Clinical Oncology, vol. 15, no. 3, pp. 987-993, 1997.
[12] R. F. Ozols, "Treatment of recurrent ovarian cancer: increasing options - 'Recurrent' results," Journal of Clinical Oncology, vol. 15, no. 6, pp. 2177-2180, 1997.

[13] W. T. B. Huinink, M. Gore, J. Carmichael et al., "Topotecan versus paclitaxel for the treatment of recurrent epithelial ovarian cancer," Journal of Clinical Oncology, vol. 15, no. 6, pp. 2183-2193, 1997.

[14] M. A. Bookman, H. Malmström, G. Bolis et al., "Topotecan for the treatment of advanced epithelial ovarian cancer: an open-label phase II study in patients treated after prior chemotherapy that contained cisplatin or carboplatin and paclitaxel," Journal of Clinical Oncology, vol. 16, no. 10, pp. 3345-3352, 1998.

[15] P. G. Rose, J. A. Blessing, A. R. Mayer, and H. D. Homesley, "Prolonged oral etoposide as second-line therapy for platinum-resistant and platinum-sensitive ovarian carcinoma: a gynecologic oncology group study," Journal of Clinical Oncology, vol. 16, no. 2, pp. 405-410, 1998.

[16] C. Percy and C. Muir, "The international comparability of cancer mortality data. Results of an international death certificate study," American Journal of Epidemiology, vol. 129, no. 5, pp. 934-946, 1989.

[17] H. T. Lynch, P. Watson, J. F. Lynch, T. A. Conway, and M. Fili, "Hereditary ovarian cancer: heterogeneity in age at onset," Cancer, vol. 71, no. 2, supplement, pp. 573-581, 1993.

[18] B. L. Harlow and N. S. Weiss, "Familial ovarian cancer: a population-based case-control study," American Journal of Epidemiology, vol. 130, no. 5, pp. 1071-1072, 1989.

[19] E. Negri, S. Franceschi, A. Tzonou et al., "Pooled analysis of 3 European case-control studies: I. Reproductive factors and risk of epithelial ovarian cancer," International Journal of Cancer, vol. 49, no. 1, pp. 50-56, 1991.

[20] L. Villard-Mackintosh, M. P. Vessey, and L. Jones, "The effects of oral contraceptives and parity on ovarian cancer trends in women under 55 years of age," British Journal of Obstetrics and Gynaecology, vol. 96, no. 7, pp. 783-788, 1989.

[21] A. P. Schneider II, "Risk factor for ovarian cancer," The New England Journal of Medicine, vol. 317, no. 8, pp. 508-509, 1987.

[22] J. T. Casagrande, E. W. Louie, and M. C. Pike, "'Incessant ovulation' and ovarian cancer," The Lancet, vol. 2, no. 8135, pp. 170-173, 1979.

[23] H. Kuper, L. Titus-Ernstoff, B. L. Harlow, and D. W. Cramer, "Population based study of coffee, alcohol and tobacco use and risk of ovarian cancer," International Journal of Cancer, vol. 88, no. 2, pp. 313-318, 2000.

[24] K. M. Fairfield, S. E. Hankinson, B. A. Rosner, D. J. Hunter, G. A. Colditz, and W. C. Willett, "Risk of ovarian carcinoma and consumption of vitamins $\mathrm{A}, \mathrm{C}$, and $\mathrm{E}$ and specific carotenoids: a prospective analysis," Cancer, vol. 92, no. 9, pp. 2318-2326, 2001.

[25] S. H. Olson, L. Mignone, C. Nakraseive, T. A. Caputo, R. R. Barakat, and S. Harlap, "Symptoms of ovarian cancer," Obstetrics and Gynecology, vol. 98, no. 2, pp. 212-217, 2001.

[26] N. Einhorn, K. Sjovall, R. C. Knapp et al., "Prospective evaluation of serum CA 125 levels for early detection of ovarian cancer," Obstetrics and Gynecology, vol. 80, no. 1, pp. 14-18, 1992.

[27] Y. Carmi, E. Voronov, S. Dotan et al., "The role of macrophage-derived IL-1 in induction and maintenance of angiogenesis," Journal of Immunology, vol. 183, no. 7, pp. 4705-4714, 2009. 
[28] R. N. Apte, Y. Krelin, X. Song et al., "Effects of microenvironment- and malignant cell-derived interleukin-1 in carcinogenesis, tumour invasiveness and tumour-host interactions," European Journal of Cancer, vol. 42, no. 6, pp. 751759, 2006.

[29] X. Song, E. Voronov, T. Dvorkin et al., "Differential effects of IL- $1 \alpha$ and IL- $1 \beta$ on tumorigenicity patterns and invasiveness," Journal of Immunology, vol. 171, no. 12, pp. 6448-6456, 2003.

[30] E. Voronov, Y. Weinstein, D. Benharroch et al., "Antitumor and immunotherapeutic effects of activated invasive T lymphoma cells that display short-term interleukin $1 \alpha$ expression," Cancer Research, vol. 59, no. 5, pp. 1029-1035, 1999.

[31] C. A. Dinarello, "Why not treat human cancer with interleukin-1 blockade?" Cancer and Metastasis Reviews, vol. 29, no. 2, pp. 317-329, 2010.

[32] M. Zoller, A. Douvdevani, S. Segal, and R. N. Apte, "Interleukin-1 produced by tumorigenic fibroblasts influences tumor rejection," International Journal of Cancer, vol. 50, no. 3, pp. 443-449, 1992.

[33] M. Zoller, A. Douvdevani, S. Segal, and R. N. Apte, "Interleukin-1 production by transformed fibroblasts. II. Influence on antigen presentation and T-cell-mediated antitumor response," International Journal of Cancer, vol. 50, no. 3, pp. 450-457, 1992.

[34] S. Vadhan-Raj, A. P. Kudelka, L. Garrison et al., "Effects of interleukin- $1 \alpha$ on carboplatin-induced thrombocytopenia in patients with recurrent ovarian cancer," Journal of Clinical Oncology, vol. 12, no. 4, pp. 707-714, 1994.

[35] J. W. Smith, W. J. Urba, B. D. Curti et al., "The toxic and hematologic effects of interleukin-1 alpha administered in a phase I trial to patients with advanced malignancies," Journal of Clinical Oncology, vol. 10, no. 7, pp. 1141-1152, 1992.

[36] C. Denkert, I. Koch, S. Berger, M. Köbel, A. Siegert, and S. Hauptmann, "Cytokine-suppressive anti-inflammatory drugs (CSAIDs) inhibit invasion and MMP-1 production of ovarian carcinoma cells," Cancer Letters, vol. 195, no. 1, pp. 101-109, 2003.

[37] S. Stadlmann, A. Amberger, J. Pollheimer et al., "Ovarian carcinoma cells and IL- $1 \beta$-activated human peritoneal mesothelial cells are possible sources of vascular endothelial growth factor in inflammatory and malignant peritoneal effusions," Gynecologic Oncology, vol. 97, no. 3, pp. 784-789, 2005.

[38] H. Chen, W. W. Yang, Q. T. Wen, LI. Xu, and M. Chen, “TGF$\beta$-induced fibroblast activation protein expression, fibroblast activation protein expression increases the proliferation, adhesion, and migration of HO-8910PM," Experimental and Molecular Pathology, vol. 87, no. 3, pp. 189-194, 2009.

[39] C. A. Dinarello, "Immunological and inflammatory functions of the interleukin-1 family," Annual Review of Immunology, vol. 27, pp. 519-550, 2009.

[40] A. Mustea, C. Pirvulescu, D. Könsgen et al., "Decreased IL1 RA concentration in ascites is associated with a significant improvement in overall survival in ovarian cancer," Cytokine, vol. 42, no. 1, pp. 77-84, 2008.

[41] E. L. Spaeth, J. L. Dembinski, A. K. Sasser et al., "Mesenchymal stem cell transition to tumor-associated fibroblasts contributes to fibrovascular network expansion and tumor progression," PLoS ONE, vol. 4, no. 4, Article ID e4992, 2009.

[42] M. B. Nilsson, R. R. Langley, and I. J. Fidler, "Interleukin6 , secreted by human ovarian carcinoma cells, is a potent proangiogenic cytokine," Cancer Research, vol. 65, no. 23, pp. 10794-10800, 2005.
[43] A. Rabinovich, L. Medina, B. Piura, S. Segal, and M. Huleihel, "Regulation of ovarian carcinoma SKOV-3 cell proliferation and secretion of MMPs by autocrine IL-6," Anticancer Research A, vol. 27, no. 1, pp. 267-272, 2007.

[44] N. H. Obata, K. Tamakoshi, K. Shibata, F. Kikkawa, and Y. Tomoda, "Effects of Interleukin-6 on in vitro cell attachment, migration and invasion of human ovarian carcinoma," Anticancer Research A, vol. 17, no. 1, pp. 337-342, 1997.

[45] Y. Wang, X. L. Niu, Y. Qu et al., "Autocrine production of interleukin-6 confers cisplatin and paclitaxel resistance in ovarian cancer cells," Cancer Letters, vol. 295, no. 1, pp. 110$123,2010$.

[46] G. Scambia, U. Testa, P. Benedetti Panici et al., "Prognostic significance of interleukin 6 serum levels in patients with ovarian cancer," British Journal of Cancer, vol. 71, no. 2, pp. 354-356, 1995.

[47] R. T. Penson, K. Kronish, Z. Duan et al., "Cytokines IL-1 $\beta$, IL-2, IL-6, IL-8, MCP-1, GM-CSF and TNF $\alpha$ in patients with epithelial ovarian cancer and their relationship to treatment with paclitaxel," International Journal of Gynecological Cancer, vol. 10, no. 1, pp. 33-41, 2000.

[48] V. D’Hondt, Y. Humblet, T. Guillaume et al., "Thrombopoietic effects and toxicity of interleukin-6 in patients with ovarian cancer before and after chemotherapy: a multicentric placebo- controlled, randomized phase Ib study," Blood, vol. 85, no. 9, pp. 2347-2353, 1995.

[49] T. Edgell, G. Martin-Roussety, G. Barker et al., "Phase II biomarker trial of a multimarker diagnostic for ovarian cancer," Journal of Cancer Research and Clinical Oncology, vol. 136, no. 7, pp. 1079-1088, 2010.

[50] E. A. Jarboe, A. K. Folkins, R. Drapkin, T. A. Ince, E. S. Agoston, and C. P. Crum, "Tubal and ovarian pathways to pelvic epithelial cancer: a pathological perspective," Histopathology, vol. 53, no. 2, pp. 127-138, 2008.

[51] N. Auersperg, S. L. Maines-Bandiera, H. G. Dyck, and P. A. Kruk, "Characterization of cultured human ovarian surface epithelial cells: phenotypic plasticity and premalignant changes," Laboratory Investigation, vol. 71, no. 4, pp. 510-518, 1994.

[52] P. A. Kruk and N. Auersperg, "Human ovarian surface epithelial cells are capable of physically restructuring extracellular matrix," American Journal of Obstetrics and Gynecology, vol. 167, no. 5, pp. 1437-1443, 1992.

[53] P. A. Kruk, V. J. Uitto, J. D. Firth, S. Dedhar, and N. Auersperg, "Reciprocal interactions between human ovarian surface epithelial cells and adjacent extracellular matrix," Experimental Cell Research, vol. 215, no. 1, pp. 97-108, 1994.

[54] N. Auersperg, I. A. Maclaren, and P. A. Kruk, "Ovarian surface epithelium: autonomous production of connective tissue-type extracellular matrix," Biology of Reproduction, vol. 44, no. 4, pp. 717-724, 1991.

[55] D. Vergara, B. Merlot, J. P. Lucot et al., "Epithelialmesenchymal transition in ovarian cancer," Cancer Letters, vol. 291, no. 1, pp. 59-66, 2010.

[56] B. Gondos, "Surface epithelium of the developing ovary. Possible correlation with ovarian neoplasia," American Journal of Pathology, vol. 81, no. 2, pp. 303-312, 1975.

[57] W. Shan and J. Liu, "Inflammation: a hidden path to breaking the spell of ovarian cancer," Cell Cycle, vol. 8, no. 19, pp. 3107-3111, 2009.

[58] R. B. Ness, J. A. Grisso, C. Cottreau et al., "Factors related to inflammation of the ovarian epithelium and risk of ovarian cancer," Epidemiology, vol. 11, no. 2, pp. 111-117, 2000. 
[59] L. S. Angelo and R. Kurzrock, "Vascular endothelial growth factor and its relationship to inflammatory mediators," Clinical Cancer Research, vol. 13, no. 10, pp. 2825-2830, 2007.

[60] N. Auersperg, J. Pan, B. D. Grove et al., "E-cadherin induces mesenchymal-to-epithelial transition in human ovarian surface epithelium," Proceedings of the National Academy of Sciences of the United States of America, vol. 96, no. 11, pp. 6249-6254, 1999.

[61] S. Elloul, O. Vaksman, H. T. Stavnes, C. G. Trope, B. Davidson, and R. Reich, "Mesenchymal-to-epithelial transition determinants as characteristics of ovarian carcinoma effusions," Clinical and Experimental Metastasis, vol. 27, no. 3, pp. 161-172, 2010.

[62] J. P. Their, "Epithelial-mesenchymal transitions in tumor progression," Nature Reviews Cancer, vol. 2, no. 6, pp. 442 454, 2002.

[63] K. Kitagawa, A. Murata, N. Matsuura et al., "Epithelialmesenchymal transformation of a newly established cell line from ovarian adenosarcoma by transforming growth factor$\beta 1$," International Journal of Cancer, vol. 66, no. 1, pp. 91-97, 1996.

[64] N. Ahmed, S. Maines-Bandiera, M. A. Quinn, W. G. Unger, S. Dedhar, and N. Auersperg, "Molecular pathways regulating EGF-induced epithelio-mesenchymal transition in human ovarian surface epithelium," American Journal of Physiology, vol. 290, no. 6, pp. C1532-C1542, 2006.

[65] Y. L. Pon, H. Y. Zhou, A. N. Y. Cheung, H. Y. S. Ngan, and A. S. T. Wong, "p70 S6 kinase promotes epithelial to mesenchymal transition through snail induction in ovarian cancer cells," Cancer Research, vol. 68, no. 16, pp. 6524-6532, 2008.

[66] L. Rosanò, F. Spinella, V. Di Castro et al., "Endothelin1 promotes epithelial-to-mesenchymal transition in human ovarian cancer cells," Cancer Research, vol. 65, no. 24, pp. 11649-11657, 2005.

[67] B. L. Thériault, T. G. Shepherd, M. L. Mujoomdar, and M. W. Nachtigal, "BMP4 induces EMT and Rho GTPase activation in human ovarian cancer cells," Carcinogenesis, vol. 28, no. 6, pp. 1153-1162, 2007.

[68] M. Colomiere, A. C. Ward, C. Riley et al., "Cross talk of signals between EGFR and IL-6R through JAK2/STAT3 mediate epithelial-mesenchymal transition in ovarian carcinomas," British Journal of Cancer, vol. 100, no. 1, pp. 134-144, 2009.

[69] H. Kajiyama, K. Shibata, M. Terauchi et al., "Chemoresistance to paclitaxel induces epithelial-mesenchymal transition and enhances metastatic potential for epithelial ovarian carcinoma cells," International Journal of Oncology, vol. 31, no. 2, pp. 277-283, 2007.

[70] F. Collino, A. Revelli, M. Massobrio et al., "Epithelialmesenchymal transition of ovarian tumor cells induces an angiogenic monocyte cell population," Experimental Cell Research, vol. 315, no. 17, pp. 2982-2994, 2009.

[71] M. A. Merritt, A. C. Green, C. M. Nagle et al., "Talcum powder, chronic pelvic inflammation and NSAIDs in relation to risk of epithelial ovarian cancer," International Journal of Cancer, vol. 122, no. 1, pp. 170-176, 2008.

[72] A. Tavani, S. Gallus, C. La Vecchia, E. Conti, M. Montella, and S. Franceschi, "Aspirin and ovarian cancer: an italian casecontrol study," Annals of Oncology, vol. 11, no. 9, pp. 1171$1173,2000$.

[73] T. Sueblinvong and M. E. Carney, "Current understanding of risk factors for ovarian cancer," Current Treatment Options in Oncology, vol. 10, no. 1-2, pp. 67-81, 2009.
[74] M. A. McSorley, A. J. Alberg, D. S. Allen et al., "C-reactive protein concentrations and subsequent ovarian cancer risk," Obstetrics and Gynecology, vol. 109, no. 4, pp. 933-941, 2007.

[75] R. B. Ness and F. Modugno, "Endometriosis as a model for inflammation-hormone interactions in ovarian and breast cancers," European Journal of Cancer, vol. 42, no. 6, pp. 691703, 2006.

[76] S. C. Mok, J. Kwong, W. R. Welch et al., "Etiology and pathogenesis of epithelial ovarian cancer," Disease Markers, vol. 23, no. 5-6, pp. 367-376, 2007.

[77] M. Mandai, K. Yamaguchi, N. Matsumura, T. Baba, and I. Konishi, "Ovarian cancer in endometriosis: molecular biology, pathology, and clinical management," International Journal of Clinical Oncology, vol. 14, no. 5, pp. 383-391, 2009.

[78] Y. Yamada, H. Shigetomi, A. Onogi et al., "New insights into pattern recognition receptors and their ligands in gynecologic pathologies," Human Immunology, vol. 72, no. 3, pp. 213-218, 2011.

[79] R. B. Ness, "Endometriosis and ovarian cancer: thoughts on shared pathophysiology," American Journal of Obstetrics and Gynecology, vol. 189, no. 1, pp. 280-294, 2003.

[80] A. G. J. van der Zee, E. M. J. De Cuyper, P. C. Limburg et al., "Higher levels of interleukin-6 in cystic fluids from patients with malignant versus benign ovarian tumors correlate with decreased hemoglobin levels and increased platelet counts," Cancer, vol. 75, no. 4, pp. 1004-1009, 1995.

[81] H. Tilg, C. A. Dinarello, and J. W. Mier, "IL-6 and APPs: anti-inflammatory and immunosuppressive mediators," Immunology Today, vol. 18, no. 9, pp. 428-432, 1997.

[82] N. Paland, I. Kamer, I. Kogan-Sakin, S. Madar, N. Goldfinger, and V. Rotter, "Differential influence of normal and cancerassociated fibroblasts on the growth of human epithelial cells in an in vitro cocultivation model of prostate cancer," Molecular Cancer Research, vol. 7, no. 8, pp. 1212-1223, 2009.

[83] W. C. Gorospe and B. L. Spangelo, "Interleukin-6 production by rat granulosa cells in vitro: effects of cytokines, folliclestimulating hormone, and cyclic 3',5'-adenosine monophosphate," Biology of Reproduction, vol. 48, no. 3, pp. 538-543, 1993.

[84] Y. J. Lidor, F. J. Xu, O. Martinez-Maza et al., "Constitutive production of macrophage colony-stimulating factor and interleukin-6 by human ovarian surface epithelial cells," Experimental Cell Research, vol. 207, no. 2, pp. 332-339, 1993.

[85] J. M. Waton, J. L. Sensintaffar, J. S. Berek, and O. MartinezMaza, "Constitutive production of interleukin 6 by ovarian cancer cell lines and by primary ovrian tumor cultures," Cancer Research, vol. 50, no. 21, pp. 6959-6965, 1990.

[86] J. G. W. Asschert, E. Vellenga, H. Hollema, A. G. J. Van Der Zee, and E. G. E. De Vries, "Expression of macrophage colony-stimulating factor (M-CSF), interleukin-6 (IL-6), interleukin-1 $\beta$ (IL-1 $\beta$ ), interleukin-11 (IL-11) and tumour necrosis factor- $\alpha$ (TNF- $\alpha$ ) in p53-characterised human ovarian carcinomas," European Journal of Cancer, vol. 33, no. 13, pp. 2246-2251, 1997.

[87] A. Erroi, M. Sironi, F. Chiaffarino, C. Zhen-Guo, M. Mengozzi, and A. Mantovani, "IL-1 and IL-6 release by tumorassociated macrophages from human ovarian carcinoma," International Journal of Cancer, vol. 44, no. 5, pp. 795-801, 1989.

[88] J. S. Berek, C. Chung, K. Kaldi, J. M. Watson, R. M. Knox, and O. Martinez-Maza, "Serum interleukin-6 levels correlate with disease status in patients with epithelial ovarian cancer," American Journal of Obstetrics and Gynecology, vol. 164, no. 4, pp. 1038-1043, 1991. 
[89] G. Gastl, M. Plante, C. L. Finstad et al., "High IL-6 levels in ascitic fluid correlate with reactive thrombocytosis in patients with epithelial ovarian cancer," British Journal of Haematology, vol. 83, no. 3, pp. 433-441, 1993.

[90] N. Auersperg, A. S. T. Wong, K. C. Choi, S. K. Kang, and P. C. K. Leung, "Ovarian surface epithelium: biology, endocrinology, and pathology," Endocrine Reviews, vol. 22, no. 2, pp. 255-288, 2001.

[91] F. A. Offner, P. Obrist, S. Stadlmann et al., "IL-6 secretion by human peritoneal mesothelial and ovarian cancer cells," Cytokine, vol. 7, no. 6, pp. 542-547, 1995.

[92] C. A. Dinarello, "Biologic basis for interleukin-1 in disease," Blood, vol. 87, no. 6, pp. 2095-2147, 1996.

[93] E. Stylianou and J. Saklatvala, "Interleukin-1," International Journal of Biochemistry and Cell Biology, vol. 30, no. 10, pp. 1075-1079, 1998.

[94] H. J. Ziltener, S. Maines-Bandiera, J. W. Schrader, and N. Auersperg, "Secretion of bioactive interleukin-1, interleukin6 , and colony- stimulating factors by human ovarian surface epithelium," Biology of Reproduction, vol. 49, no. 3, pp. 635641, 1993.

[95] A. M. Lewis, S. Varghese, H. Xu, and H. R. Alexander, "Interleukin-1 and cancer progression: the emerging role of interleukin-1 receptor antagonist as a novel therapeutic agent in cancer treatment," Journal of Translational Medicine, vol. 4, article 48, 2006.

[96] I. Cohen, P. Rider, Y. Carmi et al., "Differential release of chromatin-bound IL- $1 \alpha$ discriminates between necrotic and apoptotic cell death by the ability to induce sterile inflammation," Proceedings of the National Academy of Sciences of the United States of America, vol. 107, no. 6, pp. 2574-2579, 2010.

[97] C. A. Dinarello, "The paradox of pro-inflammatory cytokines in cancer," Cancer and Metastasis Reviews, vol. 25, no. 3, pp. 307-313, 2006.

[98] W. P. Arend, G. Palmer, and C. Gabay, "IL-1, IL-18, and IL-33 families of cytokines," Immunological Reviews, vol. 223, no. 1, pp. 20-38, 2008.

[99] R. A. Burger, E. A. Grosen, G. R. Ioli et al., "Host-tumor interaction in ovarian cancer: spontaneous release of tumor necrosis factor and interleukin-1 inhibitors by purified cell populations from human ovarian carcinoma in vitro," Gynecologic Oncology, vol. 55, no. 2, pp. 294-303, 1994.

[100] P. Y. K. Yong, C. Harlow, K. J. Thong, and S. G. Hillier, "Regulation of $11 \beta$-hydroxysteroid dehydrogenase type 1 gene expression in human ovarian surface epithelial cells by interleukin-1," Human Reproduction, vol. 17, no. 9, pp. 23002306, 2002.

[101] M. T. Rae, D. Niven, A. Ross et al., "Steroid signalling in human ovarian surface epithelial cells: the response to interleukin- $1 \alpha$ determined by microarray analysis," Journal of Endocrinology, vol. 183, no. 1, pp. 19-28, 2004.

[102] S. G. Hillier and M. Tetsuka, "An anti-inflammatory role for glucocorticoids in the ovaries?" Journal of Reproductive Immunology, vol. 39, no. 1-2, pp. 21-27, 1998.

[103] S. Temkin, V. L. Nacharaju, M. Hellman, Y. C. Lee, and O. Abulafia, "Type $211 \beta$-hydroxysteroid dehydrogenase activity in human ovarian cancer," Steroids, vol. 71, no. 11-12, pp. 1019-1023, 2006.

[104] O. Gubbay, W. Guo, M. T. Rae, D. Niven, S. P. Langdon, and S. G. Hillier, "Inflammation-associated gene expression is altered between normal human ovarian surface epithelial cells and cell lines derived from ovarian adenocarcinomas," British Journal of Cancer, vol. 92, no. 10, pp. 1927-1933, 2005.
[105] E. H. Rabbitt, N. J. L. Gittoes, P. M. Stewart, and M. Hewison, "11 $\beta$-hydroxysteroid dehydrogenases, cell proliferation and malignancy," Journal of Steroid Biochemistry and Molecular Biology, vol. 85, no. 2-5, pp. 415-421, 2003.

[106] C. F. Verschraegen, A. P. Kudelka, W. Termrungruanglert et al., "Effects of interleukin-la on ovarian carcinoma in patients with recurrent disease," European Journal of Cancer Part A, vol. 32, no. 9, pp. 1609-1611, 1996.

[107] J. Crown, A. Jakubowski, N. Kemeny et al., "A phase I trial of recombinant human interleukin- $1 \beta$ alone and in combination with myelosuppressive doses of 5-fluorouracil in patients with gastrointestinal cancer," Blood, vol. 78, no. 6, pp. 1420-1427, 1991.

[108] I. Mitroulis, P. Skendros, and K. Ritis, "Targeting IL-1 $\beta$ in disease; the expanding role of NLRP3 inflammasome," European Journal of Internal Medicine, vol. 21, no. 3, pp. 157$163,2010$. 


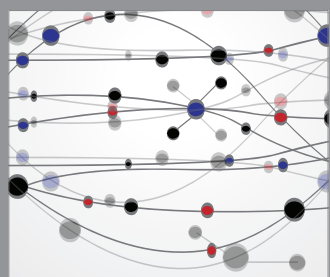

The Scientific World Journal
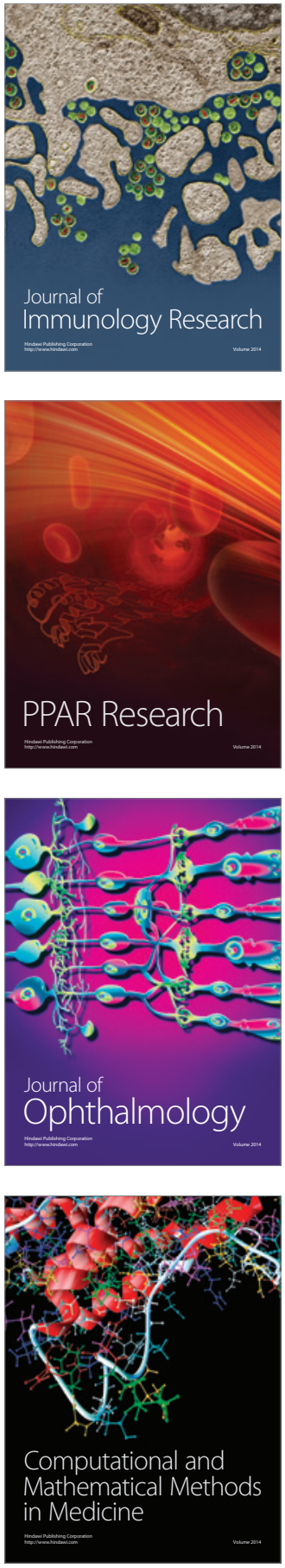

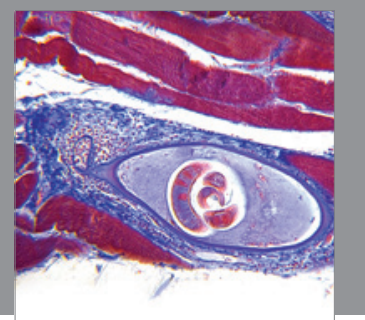

Gastroenterology

Research and Practice
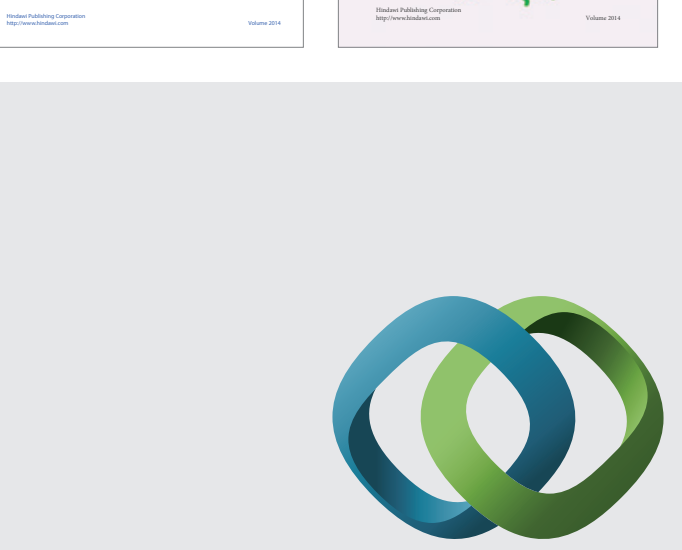

\section{Hindawi}

Submit your manuscripts at

http://www.hindawi.com
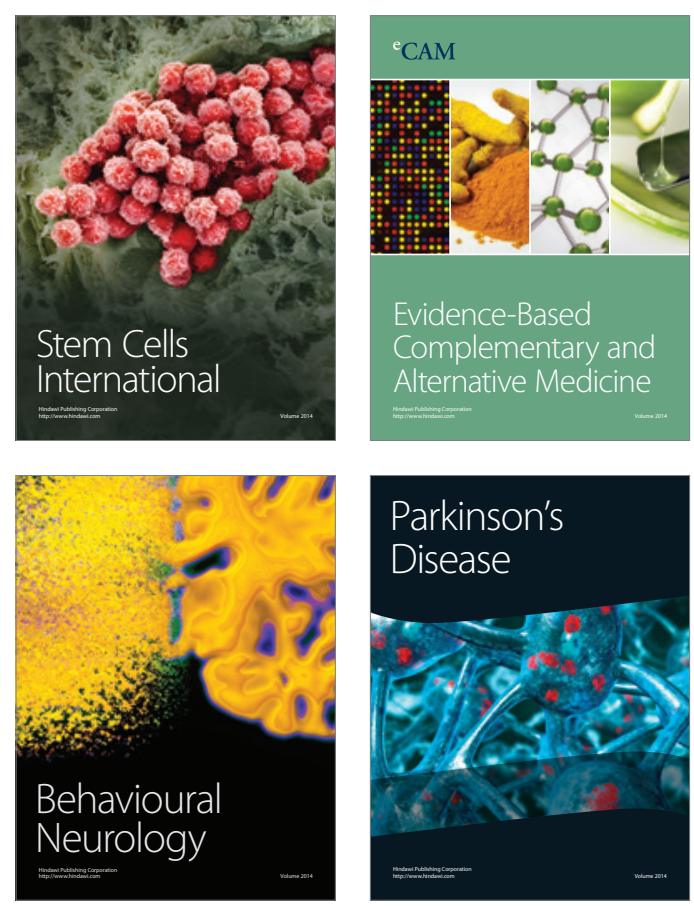

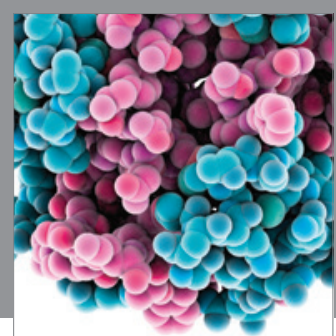

Journal of
Diabetes Research

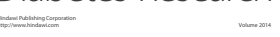

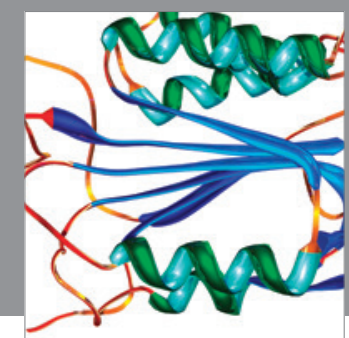

Disease Markers
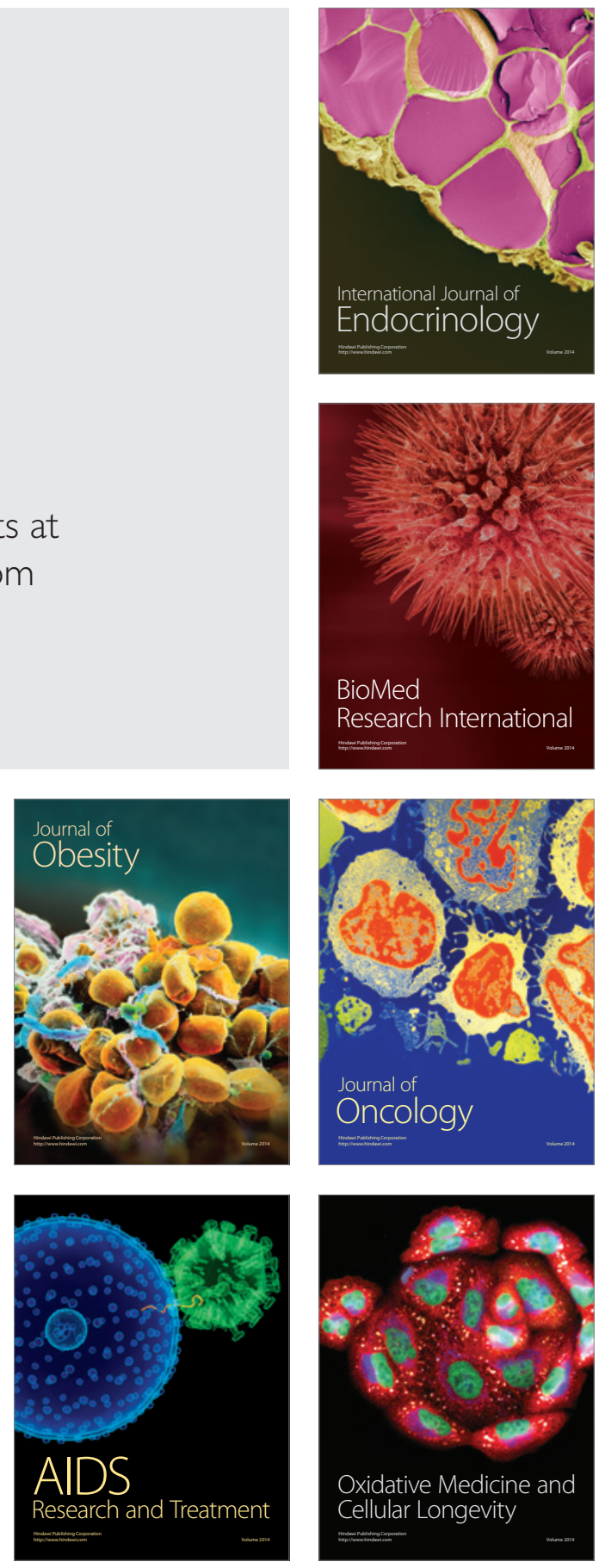